\title{
The Characteristics of the Violence against Women in Mozambique
}

\author{
Germano Vera Cruz ${ }^{1}$, Lidia Domingos ${ }^{2}$, Aniceto Sabune ${ }^{2}$ \\ ${ }^{1}$ Psychology Faculty, University of Toulouse II, Toulouse, France \\ ${ }^{2}$ Education Faculty, Eduardo Mondlane University, Maputo, Mozambique \\ Email: germanoveracruz@gmail.com, lidiacdomingos@yahoo.com.br, anicetosabune@gmail.com
}

Received 29 April 2014; revised 10 June 2014; accepted 26 June 2014

Copyright (C) 2014 by authors and Scientific Research Publishing Inc.

This work is licensed under the Creative Commons Attribution International License (CC BY).

http://creativecommons.org/licenses/by/4.0/

(c) (i) Open Access

\section{Abstract}

The purpose of this study is to identify the main characteristics of violence against women in the context of a) intimate partner relationships and b) non-partner relationships in Mozambique, using the Revised Conflict Tactics Scale (CTS2); measure the occurrence during lifetime or the past 12 months, and examine the association between intimate partner violence (IPV)/non-partner violence (NPV) types and predictor variables (demographic, socio-economic and lifestyle factors). A total of 1200 women (aged 15 - 45 years) were recruited to participate in this study. Results show that in Mozambique, generally, the rates of IPV and NPV are higher compared to those of other Sub-Saharan Africa countries (except when it comes to sexual assault). It seems that there is more violence against women within intimate partner relationship than in non-partner relationship. Adolescent, single young adults and women who experience the financial strain or use frequently alcohol are more vulnerable to be abused.

\section{Keywords}

\section{Mozambique, Relationship, Violence against Women}

\section{Introduction}

Violence against women is a gender-based violence. It is usually defined as "actions which harm or cause suffering or indignity to women, where those carrying out the actions are mainly men and where women are predominantly the victims" [1]. It seems that violence against women is a very specific type of violence, linked to the masculine dominance and patriarchal values, as well as gender roles and expectations [2]. The feminist theory asserts that power asymmetries inside the patriarchal societies create a gender social order that gives men rights and authority within the family or relationship over women, which results in men exercising power and control over women in several ways including the use violence as a tool to keep power and controlling behaviour [3]. 
The violence against women can be perpetrated by an intimate partner or a non-partner person. By far, the most prevalent issue is that of Intimate Partner Violence.

Thus, intimate partner violence can be defined as "any behaviour within an intimate relationship that causes physical, psychological or sexual harm to those in the relationship" [4]. Such behavior includes: "acts of physical aggression—such as slapping, hitting, kicking and beating; psychological abuse-such as intimidation, constant belittling and humiliating; forced intercourse and other forms of sexual coercion; various controlling behaviours-such as isolating a person from their family and friends, monitoring their movements, and restricting their access to information or assistance [4]. For the purpose of this study, non-partner violence is defined as psychological, physical or sexual harm by a person that has not intimate relationship with the victim.

\subsection{Violence against Women in Sub-Saharan Africa (SSA)}

\subsubsection{Intimate Partner Violence (IPV)}

Several reports about violence against women in Africa point the fact that in African society (and even women in these contexts) do not necessarily view acts of violence within an intimate relationship as abnormal. Rape within marriage is often considered "impossible" (certainly improbable) and physical abuse is often seen as acceptable disciple [5]. This obviously results in massive under-reporting of actual abuse [4]-[6].

Anyway, multi-country compiled data about violence against women in Sub-Saharan Africa shows that [5]: In Ethiopia, $50 \%$ of women had experienced physical violence and $59 \%$ had experienced sexual violence by a partner. Furthermore, 39\% of these women had never spoken to anyone about the violence and more than a third of those who had remained silent said they considered the violence to be "normal". According the same data, in Namibia, $31 \%$ of women had suffered physical violence and $17 \%$ had experienced sexual violence by a partner; $21 \%$ of these women had never spoken to anyone about the violence they endured. In Tanzania, $47 \%$ of women had experienced physical violence and 31\% had suffered sexual violence by a partner; $30 \%$ of these women had never spoken to anyone about the violence and about half of those who had stayed silent said they considered the violence to be "normal".

In Kenya, 39.8\% of women had experienced physical violence and $15.7 \%$ of women had experienced sexual violence by a partner. In South Africa, Eastern Province, 19\% of women had experienced physical violence and $5 \%$ of women had experienced sexual violence by a partner. In South Africa, Mpulanga, 28\% of women had experienced physical violence and $7 \%$ of women had experienced sexual violence by a partner. In South Africa, Northern Cape, $27 \%$ of women had experienced physical violence and $5 \%$ of women had experienced sexual violence by a partner. In Zambia, $8 \%$ of women had experienced physical violence and 14\% of women had experienced sexual violence by a partner. In Zimbabwe, $17 \%$ of women had experienced physical violence and $25 \%$ of women had experienced sexual violence by a partner.

Generally, in SSA, psychological aggression rate ranges from 18.2\% - 51\% [4] [5] [7]-[9]. Physical assault rate ranges from 5\% - 38\% [4] [5] [7]-[9]. Physical assault with injury rate ranges from 5\% - 35\% and sexual coercion ranges from $5.2 \%$ - 44.4\% [4] [5] [7]-[9].

SSA data on the relation between intimate partner violence against women and socio-economic status are conflicting, with some studies reporting that women living in poor socio-economic conditions (e.g. unemployed) are more exposed to IPV [9] [10] whilst others suggest that empowered women (e.g. employed) are at higher risk [11] [12]. Heavy alcohol use by men and women has also been associated with IPV [9] [10].

\subsubsection{Non-Partner Violence (NPV)}

Concerning non-partner violence against women in SSA, the big issue is rape and forced sexual debut [4]-[6].

There are almost no reliable statistics readily available on rape within the continent. The one exception is South Africa, which records the highest incident of rape in the entire world. Thus, in a 2009 study on rape in South Africa by the Medical Research Council it was found that 1 in 4 men have perpetrated rape with more than half of those admitting to multiple offences [5]. South African statistics suggest that a woman is raped in South Africa every 17 seconds and that 50\% of South African women are raped at least once in their lifetime [5]. It is reported that nearly a third of South African adolescents were forced into their first sexual encounter [5].

Anyway, multi-country compiled data about violence against women in SSA shows that [5]: In Ethiopia, 5\% of women had experienced non-partner physical violence since the age of 15 years. Fathers and other male family members were the main perpetrators. Less than $1 \%$ of women reported non-partner sexual violence since the age 
of 15 years. In Namibia, 19\% of respondents reported that someone other than a partner had been physically violent towards them since the age of 15 years, whereas $6 \%$ reported sexual violence by a non-partner. The perpetrators of physical violence included teachers (26\% of women reporting such violence), boyfriends (28\%), fathers (19\%) and female family members (19\%). The most commonly mentioned perpetrators of sexual violence were boyfriends (55\%). In Tanzania, 19\% of all respondents in Dar es Salaam and 16\% in Mbeya reported that someone other than a partner had been physically violent towards them since the age of 15 years. The main perpetrators were teachers, mentioned by more than half of all women who reported physical abuse. One in 10 women had experienced sexual violence by a non-partner since the age of 15 years. The most frequently mentioned perpetrators were boyfriends and strangers. These numbers would suggest that South African rape statistics are at least 2.5 times higher than the rest of Africa.

Forced sexual debut is also an issue that seems to be significant in Sub-Saharan Africa. According data cited by Callagahn [5], female adolescents reporting forced sexual initiation are: Mozambique (19\%), Ghana (21\%), South Africa (28\%), Tanzania (29\%), and Cameroon (37\%). The issue needs to be looked at in relation to the widely held view that intercourse with a virgin is a cure for HIV especially in Southern and East Africa where HIV is most prevalent.

\subsection{Violence against Women in Mozambique}

Statistical data suggest that violence against women is widespread in Mozambique where one survey [6] showed that $54 \%$ of polled women had been subject to physical or sexual violence by a man in their lives; and one fifth of the interviewed women had experienced violence attacks in the previous years.

\subsubsection{Intimate Partner Violence}

According Romão et al. [6], in spite of the link between IPV against women and the patriarchal values which prevail in Mozambican society, intimate partner violence perpetrated against women is predominantly viewed as a private issues and this prevents a lot of women from reporting acts of violence and seeking support. Therefore, only $10 \%$ of all cases of intimate partner violence against women are reported to the police [13].

The most common reasons evocated for not reporting violence perpetrated by partner are that "the victim can deal with it alone or through the extended family" (47\%), that the violent act is considered as "not serious" (15\%) or as "private issue" (9\%), and finally "fear of retaliation from the perpetrator" $(11 \%)$. These findings clearly reflect the perceived private nature of IPV against women [6].

In addition, many families prefer to deal with cases of violence through the customary justice systems, particularly in the rural communities. Also, in some Mozambican rural communities, in general women still not contest a husband's right to punish his spouse or partner, which justifies the fact that few women report cases of violence or consider the violence as "not serious" [6].

\subsubsection{Non-Partner Violence}

Obviously, in Mozambique as elsewhere, violence against women does not only happen in intimate spheres. It also happens out of the intimate relationship and it is often characterized by sexual stalking and sexual assault that the perpetrator is often somebody known by the victim, such as relative, close friend, neighbor, colleagues and teachers [6]. In all this cases, social attitudes often tend to blame women and young girls as the ones who provoke aggression through their inappropriate conduct. This related with the notion that violence is triggered by the victim's behavior [6]. Sexual violence in particular is attributed to a natural desire or an uncontrollable passion, supposedly provoked by women.

Although offenses perpetrated by non-partners are much more likely to be reported to police than the offenses committed by the victim's partners, only $16 \%$ of non-intimate partner violence against women are reported to the police (cases of sexual assaults and sexual stalking are reported most) [13].

The most common reasons evocated for not reporting violence perpetrated by a non-partner are that "the police is not trustful institution to deal with this matter" (35\%), fear of stigmatization (31\%), the difficulty and the painful process of showing evidence of sexual assault or sexual stalking (23\%), and finally fear of retaliation from the perpetrator (11\%) [13]. These findings clearly show that women victims of sexual assault or sexual stalking perpetrated by a non-partners perceive police institutions as untruthful to solve the problem and also that they perceive society as source of stigmatization. 
Here again, many families prefer to deal with this cases of violence through the customary justice systems, particularly in the rural communities [6].

\section{Purpose of the Present Study}

As far as we know, the surveys on violence against women that were conducted in Mozambique so far are not likely to accurately describe the characteristics of this type of violence. Indeed, most of these surveys, commissioned by government agencies and feminist organizations have often used methods such poll, hardly conducive to grasp the complexity of behavior. In addition, often these surveys use concepts or typologies vague such as those of "domestic violence".

Other studies have focused on intimate partner violence [9], but without a particularly focus on violence against women, and, most importantly, this studies used a small or a one region located samples.

Thus, given the seriousness of the problem and the lack of empirical data rigorously established, it seems necessary to carry on a study that is likely to provide more information and clarity on the issue of violence against women in Mozambique.

The purpose of this study is to identify the main characteristics (types) of violence against women in the context of a) intimate partner relationships and b) no-partner relationships. That is, describe the type of violence that women experience (psychological aggression, physical assault, physical assault with injury, sexual coercion, sexual stalking and sexual assault), measure the occurrence during the lifetime or the past 12 months, and examine the association between the types of violence experienced and demographics, socio-economic and victim lifestyles.

\section{Methodology}

\subsection{Participants}

A total of 1200 women (aged 15 - 45 years) living in five Mozambican provinces (Maputo, Inhambane, Sofala, Zambézia and Cabo Delgado) out of 10 were recruited to participate in this study (from a total estimated population of 4,942,550 women within this age group). The participants were attending secondary's schools and universities in day and nights courses, where they were contacted (in Mozambique, the people that cannot attend school or university courses during the daytime, because of their occupational status or others reasons, can attend night courses).

Of the total of number of women recruited, 23\% were aged 15 - 17 years, $45 \%$ were aged 18 - 34 years and 32\% were aged 35 - 45 years; $31 \%$ were single, $56 \%$ were married/cohabitant, $13 \%$ were divorced/separated; $52 \%$ came from rural areas and $48 \%$ came from urban areas; $44 \%$ have only completed primary school, $56 \%$ had completed secondary school and $15 \%$ had a university degree; $26 \%$ were blue-collar, 51 (\%) were low whitecollar, 21 (\%) were middle/high white-collar, $12 \%$ were only students; $25 \%$ could not provide for their needs (greater financial strain), 74\% could sometime provide for their needs (financial strain) and 11 (\%) could often provide for their needs (good financial condition); 19\% frequently drinking alcohol and 14\% frequently going out to party.

Of the total number of women recruited, 532 participants answered the questionnaire on intimate partner violence against women and 668 participants answered the questionnaire on non-intimate partner violence against women.

\subsection{Variables and Measure Instruments}

- First, women were asked whether they had been the victim of violence perpetrated by an intimate partner (yes or no) or a non-partner (yes or no) once in their live; the occurrence of that violence during the past 12 months (yes or no), and the frequency of violence $(1 ; 2 ; 3-5 ; 6-10 ; 11-20 ;+20$ times during the lifetime or the past 12 months).

Dependent variables:

- The types of violence against women in the context of intimate partner relationship (occurred during the past 12 month prior to the survey) were measured by a questionnaire adapted from CTS2 (Revised Conflict Tactics Scale) [15] that contains four sub-scales (psychological aggression, physical assault, physical assault with injury and sexual coercion). Theses sub-scales we used has a total number of 33 items covering psychological 
aggression, severe (e.g. my partner called me fat or ugly) and minor (e.g., my partner shouted or yelled me); physical assault, severe (e.g., my partner kicked me) and minor (e.g., my partner grabbed me); physical assault with injury, severe (e.g., I had a broken bone from a beat by my partner) and minor (e.g., I had a sprain, bruise, or small cut because of a beat by my partner); sexual coercion, severe (e.g., my partner used threats to have sex with me) and minor (e.g., my partner made me have sex without a condom); questions about chronicity (how often the acts happen) were linked to each item. The women were asked whether they had been victims of aggression reported by those items.

- The types of violence against women in non-intimate partner relationship (occurred during the lifetime) were measured by a questionnaire adapted from CTS2 scale that contains five subscales (psychological aggression, physical assault, physical assault with injury, sexual stalking and sexual assault). The sub-scales of this questionnaire has a total number of 39 items covering psychological aggression, severe (e.g. someone called me fat or ugly) and minor (e.g., someone shouted or yelled me); physical assault, severe (e.g., someone kicked me) and minor (e.g., someone grabbed me); physical assault with injury, severe (e.g., I had a broken bone from a beat by someone) and minor (e.g., I had a sprain, bruise, or small cut because of a beat by someone); sexual stalking, severe (e. g., someone insistently pressure me to have sex with him) and minor (e.g., someone is often making sexual suggestions to me); sexual assault, severe (e.g., someone raped me) and minor (e.g., someone use force to kiss me); questions about the type of relationship the victims had or have with the aggressor (an unknown person, neighbor, colleague, a person that have an kind of authority over the victim, a member of the family), and chronicity (how often the acts happen) were linked to each items. The women were asked whether they had been victims of aggression reported by those items.

Independent variables:

- Demographic variables (age: 15 - 17, 18 - 34, 35 - 45; marital status: single, married/cohabitation, divorced/ separated; women with children: yes or no; origin: urban areas, rural areas)/Socio-economic variables (education: completed primary school, completed secondary school, have a university degree; occupational status: blue-collar, low white-collar, middle/high white-collar, only studying; socio-economic status or financial condition: can she provide for her need-no/sometimes/often)/and Life-style variables (frequently drinking alcohol: yes or no; frequently going out to party: yes or no) were assessed by a questionnaire composed with items derived from a demographic and socio-economic classification system used by Mozambican Institute for Statistics.

\subsection{Procedure}

Data were collected during more than 12 months among women who were attending secondary schools and universities day and night courses, between January 2012 and February 2013. Trained female interviewers (psychology students) informed the participants about all details of the research and what was expected of them. The women were interviewed in a private room (on average 1 hour). The study was approved by the Ethical Committee of the Mozambican Ministry of Education.

\subsection{Statistical Analyses}

Data on intimate partner violence (IPV) and non-partner violence (NPV) types (psychological aggression, physical assault, physical assault with injury, sexual coercion, sexual stalking, sexual assault ) were described in form of raw figures, percentages, means $(M)$ and standard deviation $(S D)$. The relation between IPV and NPV types, demographic, socio-economic and life-style variables were examined with analysis of variance (ANOVAs) and chi-square tests $\left(\chi^{2}\right)$. The significance level for bivariate analyses was set at $\mathrm{p}<0.0125$ and for multivariate analyses at $\mathrm{p}<0.05$.

Four multiple block-wise logistic regressions were conducted to identify and quantify factors associated with IPV and NPV types during the past 12 months or the lifetime, while controlling for other possible factors. In block-wise logistic regression, variables are entered into the regression equation block by block and the contribution of each block in explaining the dependent variable is expressed as Nagelkerke $\mathrm{R}^{2}$. Each block explains part of the total variance (total model). Results were expressed in form of odds ratios (ORs) and 95\% confidence intervals $(95 \% \mathrm{CI})$.

Concerning IPV scale, the Cronbach $\alpha$ 's were 0.82 for psychological aggression, 0.74 for physical assault, 0.71 for physical assault with injury, and 0.68 for sexual coercion. Concerning NPV scale, the Cronbach $\alpha$ 's were 0.73 
for psychological aggression, 0.69 for physical assault, 0.73 for physical assault with injury, 0.83 for sexual stalking, and 0.77 for sexual assault.

\section{Results}

\subsection{Occurrence, Chronicity, Severity and Co-Occurrence of IPV and NPV}

Concerning IPV, as shown in Table 1, during the past 12 months prior to the survey, $47.5 \%$ (chronicity: $M=12.3$; $S D=13.7$ ) of the women experienced severe psychological aggression; $39 \%$ (chronicity: $M=10.8 ; S D=18.7$ ) severe physical assault; and 24.8\% (chronicity: $M=4.1 ; S D=8.6$ ) severe physical assault with injury; and 30.4\% (chronicity: $M=6.1$; $S D=15.1$ ) severe sexual coercion. Further, co-occurring IPV exposure across severity showed the following patterns: $28.9 \%$ experienced a combination of psychological aggression, physical assault and physical assault with injury; $28.1 \%$ experienced a combination of physical assault, physical assault with injury and sexual coercion; $45.3 \%$ experienced a combination of psychological aggression, physical assault and sexual coercion; and $26.4 \%$ experienced a combination of psychological aggression, physical assault with injury and sexual coercion. Finally, 31.3\% of the women experienced all IPV types; $63.2 \%$ of the women had experienced one or more IPV types, of which nearly half the number (49.5\%) of cases were severe acts.

Concerning NPV, as shown in Table 1, during their lifetime, 34.6\% (chronicity: $M=17.4 ; S D=9.2$ ) of the women experienced severe psychological aggression; $23.3 \%$ (chronicity: $M=4.3 ; S D=8.5$ ) severe physical assault; $16.5 \%$ severe physical assault with injury (chronicity: $M=2.2$; $S D=7.5$ )—in $73 \%$ of the cases, the aggressor was the father of the victim (57\%) or other family male who had authority over the victim (16\%). Further, $35 \%$ of the women experienced severe sexual stalking (chronicity: $M=22.3 ; S D=8.2$ ) and 21.3\% severe sexual assault (chronicity: $M=1.2 ; S D=0.5$ )—in $90 \%$ of the cases the aggressor was someone well known by the victim before: $35.9 \%$ family members $30.4 \%$ friend/colleague; $23.7 \%$ someone who have a authority over the victim (meanly teachers). Co-occurring NPV exposure across severity showed the following patterns: $31.7 \%$ experienced a combination of psychological aggression, physical assault and physical assault with injury; $24.2 \%$ experienced a combination of psychological aggression, physical assault and sexual stalking; 27.5 experienced a combination of psychological aggression, physical assault and sexual assault; $23.4 \%$ experienced a combination of psychological aggression, physical assault with injury and sexual stalking; $28.6 \%$ experienced a combination of psychological aggression, physical assault with injury and sexual assault; $21.5 \%$ experienced a combination of physical assault, physical assault with injury and sexual stalking; $29.4 \%$ experienced a combination of physical assault, physical assault with injury and sexual assault. Finally, $35.7 \%$ of the women experienced all NPV types; $58.4 \%$ of the women had experienced one or more NPV, of which more than half the number (53.7\%) of cases were severe acts.

\subsection{Demographics, Socio-Economics, Life-Style, IPV and NPV}

Concerning IPV: Psychologically aggressed women compared to counterparts more often were single (53.5\%; $\left.\mathrm{x}^{2}(3)=51.7, \mathrm{p}<0.0001\right)$, more often had only primary education degree $\left(44.8 \% ; \mathrm{x}^{2}(1)=8, \mathrm{p}<0.0046\right)$, more often used alcohol $\left(59.5 \% ; x^{2}(1)=22, p<0.0013\right)$, and go out to party $\left(55.5 \% ; x^{2}(1)=7, p<0.0041\right)$. Physically assaulted women compared to counterparts more often were married/cohabitant $\left(48.5 \%\right.$; $\left.x^{2}(2)=23.4, p<0.0001\right)$, more often come from rural areas $\left(62.7 \% ; \mathrm{x}^{2}(1)=31.2, \mathrm{p}<0.0001\right)$, more often had only primary education degree (39.4\%; $\left.\mathrm{x}^{2}(1)=8, \mathrm{p}<0.0015\right)$, and more often used alcohol $\left(57.2 \% ; \mathrm{x}^{2}(3)=19.6, \mathrm{p}<0.0037\right)$. Injured women compared to counterparts more often were married/cohabitation $\left(57.3 \% ; \mathrm{x}^{2}(2)=25.2, \mathrm{p}<0.0021\right)$, more often had children (56.4\%; $\left.\mathrm{x}^{2}(1)=22, \mathrm{p}<0.0031\right)$, more often come from rural areas $\left(57 \%\right.$; $\left.\mathrm{x}^{2}(1)=6.7, \mathrm{p}<0.0001\right)$, more often had only primary education degree $\left(45.9 \% ; x^{2}(1)=13, p<0.0027\right)$, experienced greater financial strain $\left(62.7 \% ; x^{2}(1)=10.2, p<0.0001\right)$, and frequently used alcohol $\left(59 \% ; x^{2}(1)=15.1, p<0.0001\right)$. Sexually coerced women more often were young adults (18 - 34 years) $\left(49.8 \% ; \mathrm{x}^{2}(2)=4.7, \mathrm{p}<0.0021\right)$, single $\left(53.5 \% ; \mathrm{x}^{2}(3)=24.7\right.$, $\mathrm{p}<0.0001)$, and experienced greater financial strain $\left(62.7 \% ; \mathrm{x}^{2}(1)=6.2, \mathrm{p}<0.0001\right)$.

Concerning NPV: Psychologically aggressed women compared to counterparts more often were single (51.2\%; $\left.\mathrm{x}^{2}(3)=47, \mathrm{p}<0.0001\right)$ and more often used alcohol $\left(62.5 \% ; \mathrm{x}^{2}(1)=9, \mathrm{p}<0.0026\right)$ and go out to party $\left(57.5 \% ; \mathrm{x}^{2}(1)\right.$ $=10, p<0.0021)$. Physically assaulted women compared to counterparts more often were single $\left(49.8 \% ; x^{2}(3)=\right.$ $54, \mathrm{p}<0.0001)$, more often used alcohol $\left(57.7 \% ; \mathrm{x}^{2}(1)=12, \mathrm{p}<0.0001\right)$ and go out to party $\left(65.2 \% ; \mathrm{x}^{2}(1)=9, \mathrm{p}\right.$ $<0.0001)$. Injured women compared to counterparts more often were single $\left(48.2 \% ; \mathrm{x}^{2}(3)=35.5, \mathrm{p}<0.0001\right)$, blue-collar workers $\left(43.2 \% ; \mathrm{x}^{2}(3)=39.4, \mathrm{p}<0.0001\right)$ and experienced greater financial strain $\left(56.3 \% ; \mathrm{x}^{2}(3)=16.1\right.$, 
Table 1. The distribution of IPV (past 12 months) and NIPV (during lifetime), occurrence, chronicity and cooccurrence among victim.






\begin{tabular}{|c|c|c|c|}
\hline \multicolumn{4}{|l|}{ Continued } \\
\hline Total & Occurrence & & $33.9 \%$ \\
\hline & Chronicity & & $1.4 ; 0.7$ \\
\hline Co-occurrence & & IPV & NPV \\
\hline Victim of: Psych. Aggr. + Phys. Ass + Phys. Ass. Injury & & $28.9 \%$ & $31.7 \%$ \\
\hline Victim of: Psych. Agrr. + Phys. Ass. Injury + Sexual Coercion & & $28.1 \%$ & \\
\hline Victim of: Psych. Aggr. + Phys. Ass. + Sexual Coercion & & $45.3 \%$ & \\
\hline Victim of: Phys. Ass. + Phys. Ass. Injury + Sexual Coercion & & $26.4 \%$ & \\
\hline Victim of: Psych Aggr. + Phys. Ass. + Sexual Stalking & & & 24.2 \\
\hline Victim of: Psych Aggr. + Phys. Ass. + Sexual Assault & & & 27.5 \\
\hline Victim of: Psych. Aggr. + Phys. Ass. Injury.+ Sexual Stalking & & & 23.4 \\
\hline Victim of: Psych. Aggr. + Phys. Ass. Injury + Sexual Assault & & & 28.6 \\
\hline Victim of: Phys. Ass. + Phys. Ass. Injury + Sexual Stalking & & & 21.5 \\
\hline Victim of: Phys. Ass. + Phys. Ass. Injury + Sexual Assault & & & 29.4 \\
\hline Victim of: Victim of all types & & $31.3 \%$ & $35.7 \%$ \\
\hline Victim of: Victim of one or more types & & $\begin{array}{c}63.2 \% \\
\text { (of which } 49.5 \% \\
\text { severe) }\end{array}$ & $\begin{array}{c}58.4 \% \\
\text { (53.7\% of which } \\
\text { severe) }\end{array}$ \\
\hline
\end{tabular}

$\mathrm{p}<0.0001)$. Sexually stalked women more often were adolescents $(15-17$ years $)\left(45.8 \% ; \mathrm{x}^{2}(2)=7.7, \mathrm{p}<0.0031\right)$, young adults $(18-34$ years $)\left(44.5 \% ; \mathrm{x}^{2}(2)=6.4, \mathrm{p}<0.0042\right)$ and single $\left(48.8 \% ; \mathrm{x}^{2}(3)=48.7, \mathrm{p}<0.0001\right)$. Sexually assaulted women more often were adolescents $\left(50.3 \% ; \mathrm{x}^{2}(2)=6.9, \mathrm{p}<0.0001\right)$, had only primary education degree $\left(47.8 \% ; \mathrm{x}^{2}(2)=12.5, \mathrm{p}<0.0026\right)$, were blue-collar workers $\left(31.2 \% ; \mathrm{x}^{2}(3)=32.7, \mathrm{p}<0.0001\right)$ and experienced greater financial strain $\left(60.9 \% ; \mathrm{x}^{2}(2)=5.5, \mathrm{p}<0.0001\right)$.

\subsection{Factors Associated with IPV and NPV}

Concerning IPV: As shown in Table 2, the likelihood of psychological aggression was higher among single women $(\mathrm{OR}=3.33 ; 95 \% \mathrm{CI}=1.27$ - 8.73) compared to married/cohabitant and divorced/separated women; higher among women who often use alcohol $(\mathrm{OR}=2.15 ; 95 \% \mathrm{CI}=1.32-7.60)$ and go out to party $(\mathrm{OR}=1.52 ; 95 \%$ $\mathrm{CI}=0.61$ - 3.85) compared to those who do not use frequently alcohol and do not often go out to party and lower among women with universities levels ( $\mathrm{OR}=0.97 ; 95 \% \mathrm{CI}=0.96$ - 0.99) compared to those with secondary levels. The likelihood of physical assault was higher among married/cohabitant women $(\mathrm{OR}=2.53$; 95\% CI $=1.22$ - 4.74) with secondary levels $(\mathrm{OR}=2.20 ; 95 \% \mathrm{CI}=1.65$ - 9.29) compared to single women with universities levels. Married/cohabitant $(\mathrm{OR}=1.95 ; 95 \% \mathrm{CI}=1.07$ - 5.24) women from rural areas $(\mathrm{OR}=1.15 ; 95 \% \mathrm{CI}=1.03$ 4.32) were more likely to experience physical assault with injury, compared to single women or to married/cohabitant women from urban areas. A blue-collar worker $(\mathrm{OR}=3.27 ; 95 \% \mathrm{CI}=1.50-8.01)$ were more likely to experience physical assault with injury compared to others. Single women $(\mathrm{OR}=2.33 ; 95 \% \mathrm{CI}=1.42-7.75)$ who were blue-collar workers $(\mathrm{OR}=1.88 ; 95 \% \mathrm{CI}=0.92-3.82)$ and experienced greater financial strain $(\mathrm{OR}=1.11$; $95 \% \mathrm{CI}=0.90-3.28$ ) were more likely to experience sexual coercion compared to others.

Concerning NPV: As shown in Table 3, the likelihood of psychological aggression was higher among single women $(\mathrm{OR}=3.17 ; 95 \% \mathrm{CI}=1.31-7.23)$ compared to married/cohabitant and divorced/separated women; higher among women who often frequently use alcohol (OR $=1.35 ; 95 \% \mathrm{CI}=0.95-1.98)$ and go out to party (OR $=2.03 ; 95 \% \mathrm{CI}=1.05-3.60$ ) compared to those who do not use frequently alcohol and do not often go out to party and lower among women with universities levels (OR $=0.58$; $95 \% \mathrm{CI}=0.67-0.89)$ compared to those with secondary levels. The likelihood of physical assault was higher among single women $(\mathrm{OR}=2.39 ; 95 \mathrm{CI}=$ 1.49 - 6.88) compared to married/cohabitant and divorced/separated women. A blue-collar worker $(\mathrm{OR}=1.75$; 
Table 2. Variables associated with IPV (past 12 months) by type among victims.

\begin{tabular}{|c|c|c|c|c|c|}
\hline \multirow[b]{3}{*}{ Indep. variables } & \multirow{3}{*}{ Dependent variables } & \multicolumn{4}{|l|}{ IPV } \\
\hline & & Psych. Aggression & Phys. Assault & Phys. Ass. Injury & Sex. Coercion \\
\hline & & $\begin{array}{l}\mathrm{N}=1200 \\
\text { OR 95\% CI }\end{array}$ & $\begin{array}{l}\mathrm{N}=1200 \\
\text { OR 95\% CI }\end{array}$ & $\begin{array}{l}\mathrm{N}=1200 \\
\text { OR } 95 \% \mathrm{CI}\end{array}$ & $\begin{array}{l}\mathrm{N}=1200 \\
\text { OR } 95 \% \mathrm{CI}\end{array}$ \\
\hline \multirow[t]{10}{*}{$\begin{array}{l}\text { Demographic } \\
\text { variables }\end{array}$} & $15-17$ years & & & & \\
\hline & $18-34$ years & & & & \\
\hline & $35-45$ years & & & & \\
\hline & Single & $3.33(1.27$ - 8.73) & 1 & 1 & $2.33(1.42-7.15)$ \\
\hline & Married/cohabitation & 1 & $2.53(1.22-4.74)$ & $1.95(1.07-5.24)$ & \\
\hline & Divorced/separated & 1 & & & \\
\hline & With children & & & & \\
\hline & Without children & & & & \\
\hline & Urban areas & & & 1 & \\
\hline & Rural areas & & & $1.15(1.03-4.32)$ & \\
\hline \multirow[t]{9}{*}{$\begin{array}{l}\text { Socioeconomic } \\
\text { variables }\end{array}$} & Primary sch. degree & 1 & 1 & 1 & 1 \\
\hline & Secondary sch. degree & 1 & $2.20(1.65-9.29)$ & & \\
\hline & University degree & 0.97 (0.96 - 0.99) & & & \\
\hline & Blue-collar & & & $3.27(1.50-8.01)$ & $1.88(0.92-3.82)$ \\
\hline & Low white-collar & 1 & 1 & 1 & 1 \\
\hline & Middle/high w-collar & 1 & 1 & 1 & 1 \\
\hline & Greater financial strain & & & & $1.11(0.90-3.28)$ \\
\hline & Financial strain & & & & 1 \\
\hline & Good finan. condition & 1 & 1 & 1 & 1 \\
\hline \multirow[t]{4}{*}{ Life-style variables } & Freq. drink alcohol & $2.15(1.32-7.60)$ & & & \\
\hline & Not freq. drink alcohol & 1 & 1 & 1 & 1 \\
\hline & Freq. go out to party & $1.52(0.61$ - 3.85) & & & \\
\hline & Not freq. g. out to party & 1 & 1 & 1 & 1 \\
\hline
\end{tabular}

OR = Odds Ratio; 95\% CI = 95\% confidence interval.

$95 \% \mathrm{CI}=0.97-3.85)$ were more likely to experience physical assault with injury compared to others. Adolescent $(\mathrm{OR}=3.41 ; 95 \% \mathrm{CI}=2.63-7.25)$ and young women $(\mathrm{OR}=1.45 ; 95 \% \mathrm{CI}=0.89-2.04)$ were more likely to experience sexual stalking compared to adults. Adolescent women $(\mathrm{OR}=2.99 ; 95 \% \mathrm{CI}=1.47-7.25)$ were more likely to experience sexual assault compared to young adult and adult women.

\section{Discussion}

The purpose of this study was to identify the main characteristics of violence against women in the context of a) intimate partner relationships and b) non-partner relationships, measure the IPV occurrence during the past 12 months, measure NPV occurrence during the lifetime and examine the association between IPV/NPV types and predictor variables. 
Table 3. Variables associated with NIPV (during lifetime) by type among victims.

\begin{tabular}{|c|c|c|c|c|c|c|}
\hline & Danondont xarioble & NPV & & & & \\
\hline & & Psych. Aggression & Phys. Assault & Phys. Ass. Injury & Sex. Stalking & Sex. Assault \\
\hline Indep. variab & & $N=1200$ & $\mathrm{~N}=1200$ & $\mathrm{~N}=1200$ & $\mathrm{~N}=1200$ & $\mathrm{~N}=1200$ \\
\hline $\begin{array}{l}\text { Demographic } \\
\text { variables }\end{array}$ & 15 - 17 years & & & & 3.41 (2.63- 8.17) & $2.99(1.47-7.25)$ \\
\hline & 18 - 34 years & & & & $1.45(0.89-2.04)$ & 1 \\
\hline & 35 - 45 years & & & 1 & 1 & 1 \\
\hline & Single & 3.17 (1.31 - 7.23) & $2.39(1.49-6.88)$ & & & \\
\hline & Married/cohabitation & 1 & 1 & & & \\
\hline & Divorced/Separated & 1 & 1 & & & \\
\hline & With children & & & & & \\
\hline & Without children & & & & & \\
\hline & Urban areas & & & & & \\
\hline & Rural areas & & & & & \\
\hline $\begin{array}{l}\text { Socioeconomic } \\
\text { variables }\end{array}$ & Primary sch. degree & 1 & 1 & 1 & 1 & 1 \\
\hline & Secondary sch. degree & 1 & & & & \\
\hline & University degree & $0.58(0.67-0.89)$ & & & & \\
\hline & Blue-collar & & & $1.75(0.97-3.85)$ & & \\
\hline & Low white-collar & 1 & 1 & 1 & 1 & 1 \\
\hline & Middle/high w-collar & 1 & 1 & 1 & 1 & 1 \\
\hline & Greater financial strain & & & & & \\
\hline & Financial strain & & & & & \\
\hline & Good finan. condition & & & & & \\
\hline Life-style & Freq. drink alcohol & 1.35 (0.95 - 1.98) & & & & \\
\hline & Not freq. drink alcohol & 1 & 1 & 1 & 1 & 1 \\
\hline & Freq. go out to party & $2.03(1.05-3.60)$ & & & & \\
\hline & Not freq. g. out to party & 1 & 1 & 1 & 1 & 1 \\
\hline
\end{tabular}

OR = Odds Ratio; 95\% CI = 95\% confidence interval.

\subsection{Occurrence, Chronicity and Severity of IPV and NPV}

This study showed that, concerning IPV, 63.2.\% of the women had experienced one or more IPV types during the past 12 months, of which nearly half the number $(49.5 \%)$ of cases were severe acts. Concerning NPV, results showed that $58.4 \%$ of the women had experienced one or more NPV types during their lifetime, of which more than half the number (53.7\%) of cases were severe acts. In general, the figures in this study were higher than those reported in South-Saharan Africa (SSA) and elsewhere with different population samples, which vary between 2\% - 51\% [4] [5] [7]-[9]. Differences in the operationalization of IPV, procedures and samples characteristics between our study and others may explain differences in violence rates. As for chronicity and severity, findings in our study are not comparable with those of other studies, because such data are either not provided or are reported differently. 
The most common form of IPV was psychological aggression, experienced by $64.3 \%$ of women, with severe acts amounting to $47.5 \%$. Our findings are much higher than those observed in SSA and elsewhere with various types of populations, which range from $18.2 \%$ - 51\% [4] [5] [7]-[9], and slimly lower than those recorded in a Russian study with female students using the same definition of psychological aggression (66.7\%) [16].

The results showed that physical assault was experienced by $52.3 \%$ of the women, with $39 \%$ being severe acts, are greater than those shown in SSA and elsewhere (5\% - 38\%) [4] [5] [7]-[9] excepting those reported in Canadian studies (67\% and $68 \%$ of women were exposed to minor and severe physical assault, respectively) [17]-[19].

Physical assault with injury was reported by $34.4 \%$ of the women, and $24.8 \%$ were severe acts. Our rates are consistent with those of SSA previous observations. Nonetheless, our rates are greater than those reported in a Russian study with female students using the same definition of physical assault (7.7\% were severe acts at a mean chronicity of 1.2) [16].

Sexual coercion was reported by $42.9 \%$ of the women, and $30.4 \%$ were severe acts. Our figures are consistent with those observed in Sub-Saharan Africa and elsewhere among different samples, which range from $5.2 \%$ - 44.4\% [4] [5] [7]-[9].

The most common form of MPV was also psychological aggression, experienced by $69.1 \%$ of women, with severe acts amounting 34.6\%. As we didn't find SSA data in psychological aggression committed by a nonpartner, it is not possible to compare.

Findings showed that physical assault was experienced by $34.9 \%$ of the women, with $23.3 \%$ being severe acts, are greater than those shown in SSA (5\% - 19\%). In our study the willingness of the participants to unveil their experiences of sexual abuse may explain differences in rates. The fact that the majority of aggressors (73\%) was family members (father and others males family members) is consistent with results of others studies in SSA [5].

Physical assault with injury was reported by $25.7 \%$ of the women, and $16.5 \%$ were severe acts. As we didn't find SSA data in psychological aggression committed by a non-partner, it is not possible to compare.

Sexual stalking was reported by $67.9 \%$ of the women, and $35 \%$ were severe acts. As we didn't find SSA data in psychological aggression committed by a non-partner, it is not possible to compare.

Sexual assault was reported by $33.9 \%$ of the women and $21.3 \%$ were severe acts (rape). Our figures are lower than those observed in South Africa, for example, where $50 \%$ of women have been raped at least once in their live, and lower than those from Cameroon where 37\% of women had experienced forced sexual debut [5].

The fact that the aggressor, in stalking and sexual assault cases, was someone well known by the victim (90\%) before (family members, neighbors, friends/colleagues and teachers) a consistent with results of others studies in SSA and elsewhere [5].

\subsection{Differences in Demographics/Socio-Economics/Life-Style and Correlates of IPV/NPV}

Results showed that, in general, adolescent, single young adults and women who experience financial strain or use frequently alcohol are more vulnerable to be abused. Lower educated women are also, in general, more vulnerable to male violence than higher educated women.

These results are in concordance with those from other studies reporting increased likelihood of abuse among women of low socio-economic status because of their shorted resources, economic vulnerability and limited opportunities [9] [10].

The findings that women who used alcohol more often experienced all types of abuse are in concordance with those from previous studies [9] [10]. This may be imputed to alcohol intoxication leading to irresponsible behavior, therefore increasing the likelihood of violence.

The finding that lower educational levels were positively associated with exposure to male violence may be associated with the notion that the empowerment conferred by better education counteract traditional gender roles; rather, women's lower education tends be associated with increased vulnerability to violence.

\section{Conclusion}

In Mozambique, in general, the rates of IPV and NPV are higher compared to those of other SSA countries (except when it comes to sexual assault). It seems that there is more violence against women within intimate relationship than in non-partner relationship. Adolescent, single young adults and women who experience the financial strain or use frequently alcohol are more vulnerable to be abused. 


\section{Limitations}

This study has some limitations. First, as the study is based on the women's self-reported account of their IPV and NPV experiences, it is possible that some women may under or over report their experiences according their own point of view of the degree of acceptability of the men violence against women. Second, the study (cross-sectional design) could not establish firm causal links, as that demands another type of research (e.g. longitudinal design). Third, the measurement of certain variables (e.g. alcohol use and go out to party) in a yes/no format may have been too crude to fully capture their association with IPV and with NPV. Despite these weaknesses, the results of this study bring provision of new insights to design better intervention and prevention measures. And, to be effective, we think that future studies have to measure the level of tolerance of Mozambicans towards violence against women both in the context of intimate relationships and non-intimate relationships.

\section{Policy Implications}

Findings in this study might be useful for better understanding of the characteristics of violence against women in Mozambique as well as spark a constructive debate and awareness on this issue within society. Findings in this study also have policy implications, among which to provide governmental and non-governmental organizations fighting violence against women reliable empirical data on which to base and adequate their interventions.

\section{References}

[1] Saltzman, L.E., Fanslow, J.L., McMahon, P.M. and Shelley, G.A. (2002) Intimate Partner Violence Surveillance: Uniform Definitions and Recommended Data Elements, Version 1.0. Centers for Disease Control and Prevention, National Center for Injury Prevention and Control, Atlanta.

[2] Hines, D.A. (2007) Predictors of Sexual Coercion against Women and Men: A Multilevel, Multinational Study of University Students. Archive of Sex Behaviour, 36, 403-422. http://dx.doi.org/10.1007/s10508-006-9141-4

[3] Scott, K., Straus, M.A. (2007) Denial, Minimization, Partner Blaming, and Intimate Aggression in Dating Partners. Journal of Interpersonal Violence, 22, 851-871. http://dx.doi.org/10.1177/0886260507301227

[4] WHO (World Health Organization) (2002) World Report on Violence and Health. WHO, Geneva.

[5] WHO (World Health Organization) (2005) WHO Multi-Country Study on Women's Health and Domestic Violence Against Women: Initial Results on Prevalence, Health and Outcomes and Women's Responses. WHO, Geneva.

[6] Callagham, S. (2010) Violence against Women in Sub-Saharan Africa. African Union, Addis Ababa.

[7] Romão, F., Mabunda, L., Buque, C., Samo, G. and Vieira, O. (2009) Violence against Women in Mozambique. UNIFEM, Maputo.

[8] Pico-Alfonso, M.A., Garcia-Linares, M.I., Celda-Navarro, N., Blasco-Ros, C., Echeburua, E. and Martinez, M. (2006) The Impact of Physical, Psychological, and Sexual Intimate Male Partner Violence on Women's Mental Health: Depressive Symptoms, Posttraumatic Stress Disorder, State Anxiety, and Suicide. Journal of Women's Health, 15, 599611. http://dx.doi.org/10.1089/jwh.2006.15.599

[9] Okenwa, L., Lawoko, S. and Jansson, B. (2009) Exposure to Intimate Partner Violence amongst Women of Reproductive Age in Lagos, Nigeria: Prevalence and Predictors. Journal of Family Violence, 24, 517-30. http://dx.doi.org/10.1007/s10896-009-9250-7

[10] Zacarias, A., Macassa, G., Svanstrom, L., Soares, J. and Antai, D. (2012) Intimate Partner Violence against Women in Maputo City, Mozambique. BMC International Health \& Human Right, 12, 35.

[11] Andersson, N., Ho-Foster, A., Mitchell, S., Scheepers, E. and Goldstein, S. (2007) Risk Factors for Domestic Physical Violence: National Cross-Sectional Household Surveys in Eight Southern Africa Countries. BMC Womens Health, 7, 1-13. http://dx.doi.org/10.1186/1472-6874-7-11

[12] Chakwana, C.D. (2005) Domestic Violence. National Statistical Office (NSO) [Malawi], and ORC Macro. Malawi Demographic and Health Survey 2004. NSO and ORC Macro, Calverton.

[13] ZCSO (Zimbabwean Central Statistical Office) (2005/6) Demographic and Health Survey 2005-06. CSO and Macro International Inc., Calverton.

[14] MIM (Mozambican Interior Ministry) (2011) Relatório sobre a violence doméstica em Moçambique. MIM, Maputo.

[15] Vera Cruz, G. (2010) Pesquisa Sobre a Violence Sexual junto dos Estudandes da UEM Sexual Violence Research within Mozambican Students]. Eduardo Mondlane University, Maputo.

[16] Straus, M.A., Hamby, S.L., Boney-McCoy, S. and Sugarman, D.B. (1996) The Revised Conflict Tactics Scales (CTS2): Development and Preliminary Psychometric Data. Journal of Family Issues, 17, 283-316. 
http://dx.doi.org/10.1177/019251396017003001

[17] Lysova, A.V. and Douglas, E.M. (2008) Intimate Partner Violence among Male and Female Russian University Students. Journal of Interpersonal Violence, 23, 1579-1599. http://dx.doi.org/10.1177/0886260508314320

[18] Laroche, D. (2005) Aspects of the Context and Consequences of Domestic Violence-Situational Couple Violence and Intimate Terrorism in Canada in 1999. Institute de la Statistique du Quebec, Quebec.

[19] Romans, S., Forte, T., Cohen, M.M., Du Mont, J. and Hyman, I. (2007) Who Is Most at Risk for Intimate Partner Violence? A Canadian Population-Based Study. Journal of Interpersonal Violence, 22, 1495-1514.

http://dx.doi.org/10.1177/0886260507306566 
Scientific Research Publishing (SCIRP) is one of the largest Open Access journal publishers. It is currently publishing more than 200 open access, online, peer-reviewed journals covering a wide range of academic disciplines. SCIRP serves the worldwide academic communities and contributes to the progress and application of science with its publication.

Other selected journals from SCIRP are listed as below. Submit your manuscript to us via either submit@scirp.org or Online Submission Portal.
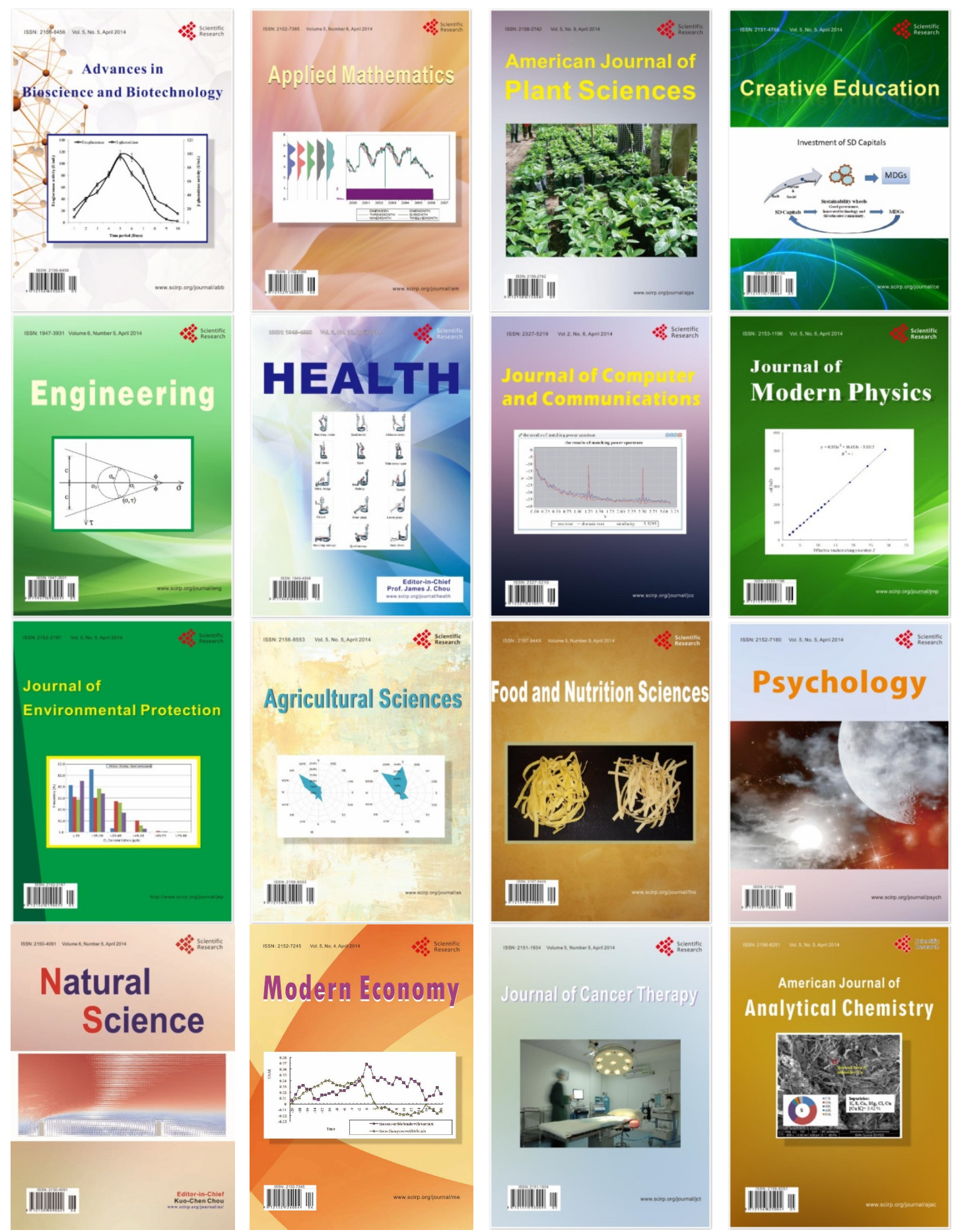